\title{
Why does peer instruction benefit student learning?
}

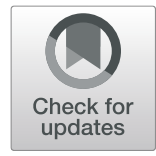

Jonathan G. Tullis ${ }^{*}$ and Robert L. Goldstone ${ }^{2}$

\begin{abstract}
In peer instruction, instructors pose a challenging question to students, students answer the question individually, students work with a partner in the class to discuss their answers, and finally students answer the question again. A large body of evidence shows that peer instruction benefits student learning. To determine the mechanism for these benefits, we collected semester-long data from six classes, involving a total of 208 undergraduate students being asked a total of 86 different questions related to their course content. For each question, students chose their answer individually, reported their confidence, discussed their answers with their partner, and then indicated their possibly revised answer and confidence again. Overall, students were more accurate and confident after discussion than before. Initially correct students were more likely to keep their answers than initially incorrect students, and this tendency was partially but not completely attributable to differences in confidence. We discuss the benefits of peer instruction in terms of differences in the coherence of explanations, social learning, and the contextual factors that influence confidence and accuracy.
\end{abstract}

Keywords: Group decisions, Peer instruction, Metacognition, Confidence, Decision making

\section{Significance}

Peer instruction is widely used in physics instruction across many universities. Here, we examine how peer instruction, or discussing one's answer with a peer, affects students' decisions about a class assignment. Across six different university classes, students answered a question, discussed their answer with a peer, and finally answered the question again. Students' accuracy consistently improved through discussion with a peer. Our peer instruction data show that students were hesitant to switch away from their initial answer and that students did consider both their own confidence and their partner's confidence when making their final decision, in accord with basic research about confidence in decision making. More broadly, the data reveal that peer discussion helped students select the correct answer by prompting them to create new knowledge. The benefit to student accuracy that arises when students discuss their answers with a partner is a "process gain", in which working in a group yields

\footnotetext{
* Correspondence: jonathantullis@gmail.com

'Department of Educational Psychology, University of Arizona, $1430 \mathrm{E}$.

Second St., Tucson, AZ 85721, USA

Full list of author information is available at the end of the article
}

better performance than can be predicted from individuals' performance alone.

Peer instruction is specific evidence-based instructional strategy that is well-known and widely used, particularly in physics (Henderson \& Dancy, 2009). In fact, peer instruction has been advocated as a part of best methods in science classrooms (Beatty, Gerace, Leonard, \& Dufresne, 2006; Caldwell, 2007; Crouch \& Mazur, 2001; Newbury \& Heiner, 2012; Wieman et al., 2009) and over a quarter of university physics professors report using peer instruction (Henderson \& Dancy, 2009). In peer instruction, instructors pose a challenging question to students, students answer the question individually, students discuss their answers with a peer in the class, and finally students answer the question again. There are variations of peer instruction in which instructors show the class's distribution of answers before discussion (Nielsen, Hansen-Nygård, \& Stav, 2012; Perez et al., 2010), in which students' answers are graded for participation or for correctness (James, 2006), and in which instructors' norms affect whether peer instruction offers opportunities for answer-seeking or for sense-making (Turpen \& Finkelstein, 2007). 
Despite wide variations in its implementation, peer instruction consistently benefits student learning. Switching classroom structure from didactic lectures to one centered around peer instruction improves learners' conceptual understanding (Duncan, 2005; Mazur, 1997), reduces student attrition in difficult courses (Lasry, Mazur, \& Watkins, 2008), decreases failure rates (Porter, Bailey-Lee, \& Simon, 2013), improves student attendance (Deslauriers, Schelew, \& Wieman, 2011), and bolsters student engagement (Lucas, 2009) and attitudes to their course (Beekes, 2006). Benefits of peer instruction have been found across many fields, including physics (Mazur, 1997; Pollock, Chasteen, Dubson, \& Perkins, 2010), biology (Knight, Wise, \& Southard, 2013; Smith, Wood, Krauter, \& Knight, 2011), chemistry (Brooks \& Koretsky, 2011), physiology (Cortright, Collins, \& DiCarlo, 2005; Rao \& DiCarlo, 2000), calculus (Lucas, 2009; Miller, Santana-Vega, \& Terrell, 2007), computer science (Porter et al., 2013), entomology (Jones, Antonenko, \& Greenwood, 2012), and even philosophy (Butchart, Handfield, \& Restall, 2009). Additionally, benefits of peer instruction have been found at prestigious private universities, two-year community colleges (Lasry et al., 2008), and even high schools (Cummings \& Roberts, 2008). Peer instruction benefits not just the specific questions posed during discussion, but also improves accuracy on later similar problems (e.g., Smith et al., 2009).

One of the consistent empirical hallmarks of peer instruction is that students' answers are more frequently correct following discussion than preceding it. For example, in introductory computer science courses, postdiscussion performance was higher on 70 out of 71 questions throughout the semester (Simon, Kohanfars, Lee, Tamayo, \& Cutts, 2010). Further, gains in performance from discussion are found on many different types of questions, including recall, application, and synthesis questions (Rao \& DiCarlo, 2000). Performance improvements are found because students are more likely to switch from an incorrect answer to the correct answer than from the correct answer to an incorrect answer. In physics, 59\% of incorrect answers switched to correct following discussion, but only $13 \%$ of correct answers switched to incorrect (Crouch \& Mazur, 2001). Other research on peer instruction shows the same patterns: $41 \%$ of incorrect answers are switched to correct ones, while only $18 \%$ of correct answers are switched to incorrect (Morgan \& Wakefield, 2012). On qualitative problem-solving questions in physiology, $57 \%$ of incorrect answers switched to correct after discussion, and only 7\% of correct answers to incorrect (Giuliodori, Lujan, \& DiCarlo, 2006).

There are two explanations for improvements in prediscussion to post-discussion accuracy. First, switches from incorrect to correct answers may be driven by selecting the answer from the peer who is more confident. When students discuss answers that disagree, they may choose whichever answer belongs to the more confident peer. Evidence about decision-making and advice-taking substantiates this account. First, confidence is correlated with correctness across many settings and procedures (Finley, Tullis, \& Benjamin, 2010). Students who are more confident in their answers are typically more likely to be correct. Second, research examining decision-making and advice-taking indicates that (1) the less confident you are, the more you value others' opinions (Granovskiy, Gold, Sumpter, \& Goldstone, 2015; Harvey \& Fischer, 1997; Yaniv, 2004a, 2004b; Yaniv \& Choshen-Hillel, 2012) and (2) the more confident the advisor is, the more strongly they influence your decision (Kuhn \& Sniezek, 1996; Price \& Stone, 2004; Sah, Moore, \& MacCoun, 2013; Sniezek \& Buckley, 1995; Van Swol \& Sniezek, 2005; Yaniv, 2004b). Consequently, if students simply choose their final answer based upon whoever is more confident, accuracy should increase from pre-discussion to post-discussion. This explanation suggests that switches in answers should be driven entirely by a combination of one's own initial confidence and one's partner's confidence. In accord with this confidence view, Koriat (2015) shows that an individual's confidence typically reflects the group's most typically given answer. When the answer most often given by group members is incorrect, peer interactions amplify the selection of and confidence in incorrect answers. Correct answers have no special draw. Rather, peer instruction merely amplifies the dominant view through differences in the individual's confidence.

In a second explanation, working with others may prompt students to verbalize explanations and verbalizations may generate new knowledge. More specifically, as students discuss the questions, they need to create a common representation of the problem and answer. Generating a common representation may compel students to identify gaps in their existing knowledge and construct new knowledge (Schwartz, 1995). Further, peer discussion may promote students' metacognitive processes of detecting and correcting errors in their mental models. Students create more new knowledge and better diagnostic tests of answers together than alone. Ultimately, then, the new knowledge and improved metacognition may make the correct answer appear more compelling or coherent than incorrect options. Peer discussion would draw attention to coherent or compelling answers, more so than students' initial confidence alone and the coherence of the correct answer would prompt students to switch away from incorrect answers. Similarly, Trouche, Sander, and Mercier (2014) argue that interactions in a group prompt argumentation and discussion of reasoning. Good arguments and reasoning should be more compelling to change individuals' answers than confidence alone. Indeed, in a reasoning task known to benefit from careful deliberation, 
good arguments and the correctness of the answers change partners' minds more than confidence in one's answer (Trouche et al., 2014). This explanation predicts several distinct patterns of data. First, as seen in prior research, more students should switch from incorrect answers to correct than vice versa. Second, the intrinsic coherence of the correct answer should attract students, so the likelihood of switching answers would be predicted by the correctness of an answer above and beyond differences in initial confidence. Third, initial confidence in an answer should not be as tightly related to initial accuracy as final confidence is to final accuracy because peer discussion should provide a strong test of the coherence of students' answers. Fourth, because the coherence of an answer is revealed through peer discussion, student confidence should increase more from pre-discussion to post-discussion when they agree on the correct answers compared to agreeing on incorrect answers.

Here, we examined the predictions of these two explanations of peer instruction across six different classes. We specifically examined whether changes in answers are driven exclusively through the confidence of the peers during discussion or whether the coherence of an answer is better constructed and revealed through peer instruction than on one's own. We are interested in analyzing cognitive processes at work in a specific, but common, implementation of classroom-based peer instruction; we do not intend to make general claims about all kinds of peer instruction or to evaluate the long-term effectiveness of peer instruction. This research is the first to analyze how confidence in one's answer relates to answer-switching during peer instruction and tests the impact of peer instruction in new domains (i.e., psychology and educational psychology classes).

\section{Method}

\section{Participants}

Students in six different classes participated as part of their normal class procedures. More details about these classes are presented in Table 1 . The authors served as instructors for these classes. Across the six classes, 208 students contributed a total of 1657 full responses to 86 different questions.

\section{Materials}

The instructors of the courses developed multiplechoice questions related to the ongoing course content. Questions were aimed at testing students' conceptual understanding, rather than factual knowledge. Consequently, questions often tested whether students could apply ideas to new settings or contexts. An example of a cognitive psychology question used is: Which is a fixed action pattern (not a reflex)?

a. Knee jerks up when patella is hit

b. Male bowerbirds building elaborate nests [correct]

c. Eye blinks when air is blown on it

d. Can play well learned song on guitar even when in conversation

\section{Procedure}

The procedures for peer instruction across the six different classes followed similar patterns. Students were presented with a multiple-choice question. First, students read the question on their own, chose their answer, and reported their confidence in their answer on a scale of 1 "Not at all confident" to 10 "Highly confident". Students then paired up with a neighbor in their class and discussed the question with their peer. After discussion, students answered the question and reported the confidence for a second time. The course instructor indicated the correct answer and discussed the reasoning for the answer after all final answers had been submitted. Instruction was paced based upon how quickly students read and answered questions. Most student responses counted towards their participation grade, regardless of the correctness of their answer (the last question in each of the cognitive psychology classes was graded for correctness).

There were small differences in procedures between classes. Students in the cognitive psychology classes input their responses using classroom clickers, but those in other classes wrote their responses on paper. Further, students in the cognitive psychology classes explicitly reported their partner's answer and confidence, while students in other classes only reported the name of their partner (the partners' data were aligned during data recording). The cognitive psychology students then were required to mention their own answer and their confidence to their partner during peer instruction; students

Table 1 Descriptions of classes used

\begin{tabular}{llllll}
\hline Class & Year & Level & Number of Students & Number of Questions & Location \\
\hline Cognitive Psych (Psych) & 2015 & Middle level undergrad & 61 & 4 & Indiana University \\
Cognitive Psych (Psych) & 2017 & Middle level undergrad & 60 & 4 & Indiana University \\
Decision Making (Ed Psych) & 2016 & Upper level undergrad & 24 & 15 & University of Arizona \\
Decision Making (Ed Psych) & 2017 & Upper level undergrad & 37 & 16 & University of Arizona \\
Learning Theories (Ed Psych) & 2016 & Intro Master's level & 12 & 26 & University of Arizona \\
Learning Theories (Ed Psych) & 2018 & Intro Master's level & 14 & 21 & University of Arizona \\
\hline
\end{tabular}


in other classes were not required to tell their answer or their confidence to their peer. Finally, the questions appeared at any point during the class period for the cognitive psychology classes, while the questions typically happened at the beginning of each class for the other classes.

\section{Results}

\section{Analytic strategy}

Data are available on the OpenScienceFramework: https://mfr.osf.io/render?url=https://osf.io/5qc46/?action $=$ download $\% 26$ mode $=$ render.

For most of our analyses we used linear mixed-effects models (Baayen, Davidson, \& Bates, 2008; Murayama, Sakaki, Yan, \& Smith, 2014). The unit of analysis in a mixed-effect model is the outcome of a single trial (e.g., whether or not a particular question was answered correctly by a particular participant). We modeled these individual trial-level outcomes as a function of multiple fixed effects - those of theoretical interest - and multiple random effects - effects for which the observed levels are sampled out of a larger population (e.g., questions, students, and classes sampled out of a population of potential questions, students, and classes).

Linear mixed-effects models solve four statistical problems involved with the data of peer instruction. First, there is large variability in students' performance and the difficulty of questions across students and classes. Mixed-effect models simultaneously account for random variation both across participants and across items (Baayen et al., 2008; Murayama et al., 2014). Second, students may miss individual classes and therefore may not provide data across every item. Similarly, classes varied in how many peer instruction questions were posed throughout the semester and the number of students enrolled. Mixed-effects models weight each response equally when drawing conclusions (rather than weighting each student or question equally) and can easily accommodate missing data. Third, we were interested in how several different characteristics influenced students' performance. Mixed effects models can include multiple predictors simultaneously, which allows us to test the effect of one predictor while controlling for others. Finally, mixed effects models can predict the log odds (or logit) of a correct answer, which is needed when examining binary outcomes (i.e., correct or incorrect; Jaeger, 2008).

We fit all models in $\mathrm{R}$ using the lmer() function of the lme4 package (Bates, Maechler, Bolker, \& Walker, 2015). For each mixed-effect model, we included random intercepts that capture baseline differences in difficulty of questions, in classes, and in students, in addition to multiple fixed effects of theoretical interest. In mixed-effect models with hundreds of observations, the $t$ distribution effectively converges to the normal, so we compared the $t$ statistic to the normal distribution for analyses involving continuous outcomes (i.e., confidence; Baayen, 2008). $P$ values can be directly obtained from Wald $\mathrm{z}$ statistics for models with binary outcomes (i.e., correctness).

\section{Does accuracy change through discussion?}

First, we examined how correctness changed across peer discussion. A logit model predicting correctness from time point (pre-discussion to post-discussion) revealed that the odds of correctness increased by 1.57 times (95\% confidence interval (conf) 1.31-1.87) from pre-discussion to post-discussion, as shown in Table 2 . In fact, $88 \%$ of students showed an increase or no change in accuracy from pre-discussion to post-discussion. Pre-discussion to postdiscussion performance for each class is shown in Table 3. We further examined how accuracy changed from prediscussion to post-discussion for each question and the results are plotted in Fig. 1. The data show a consistent improvement in accuracy from pre-discussion to postdiscussion across all levels of initial difficulty.

We examined how performance increased from prediscussion to post-discussion by tracing the correctness of answers through the discussion. Figure 2 tracks the percent (and number of items) correct from pre-discussion to post-discussion. The top row shows whether students were initially correct or incorrect in their answer; the middle row shows whether students agreed or disagreed with their partner; the last row show whether students were correct or incorrect after discussion. Additionally, Fig. 2 shows the confidence associated with each pathway. The bottow line of each entry shows the students' average confidence; in the middle white row, the confidence reported is the average of the peer's confidence.

Broadly, only $5 \%$ of correct answers were switched to incorrect, while $28 \%$ of incorrect answers were switched to correct following discussion. Even for the items in which students were initially correct but disagreed with their partner, only $21 \%$ of answers were changed to incorrect answers after discussion. However, out of the items where students were initially incorrect and disagreed with their partner, $42 \%$ were changed to the correct answer.

\section{Does confidence predict switching?}

Differences in the amount of switching to correct or incorrect answers could be driven solely by differences in confidence, as described in our first theory mentioned earlier. For this theory to hold, answers with greater

Table 2 The effect of time point (pre-discussion to postdiscussion) on accuracy using a mixed effect logit model

\begin{tabular}{lllll}
\hline Fixed Effect & $\hat{\beta}$ & SE & Wald z & $p$ \\
\hline Intercept & 0.68 & 0.19 & 3.515 & .0004 \\
Time point (pre to post) & 0.45 & 0.09 & 5.102 & $<.0001$ \\
\hline
\end{tabular}


Table 3 Accuracy before and after discussion by class

\begin{tabular}{|c|c|c|c|c|c|}
\hline Class & Pre-correct (mean) & Post-correct (mean) & SD of difference & Paired $t$ test & Cohen's a \\
\hline Cognitive Psych (Psych) 2015 & 0.67 & 0.76 & 0.27 & $t(60)=2.40, p=0.02$ & 0.31 \\
\hline Cognitive Psych (Psych) 2017 & 0.65 & 0.73 & 0.21 & $t(59)=2.75, p=0.007$ & 0.36 \\
\hline Decision Making (Ed Psych) 2016 & 0.57 & .66 & 0.13 & $t(23)=3.30, p=0.003$ & 0.69 \\
\hline Decision Making (Ed Psych) 2017 & 0.71 & 0.75 & 0.13 & $t(36)=1.92, p=0.06$ & 0.32 \\
\hline Learning Theories (Ed Psych) 2016 & 0.58 & 0.69 & 0.06 & $t(11)=5.76, p<0.001$ & 1.74 \\
\hline Learning Theories (Ed Psych) 2018 & 0.57 & 0.61 & 0.09 & $t(13)=2.00, p=0.07$ & 0.56 \\
\hline Overall & 0.65 & 0.72 & 0.20 & $t(212)=5.39, p<0.001$ & 0.37 \\
\hline
\end{tabular}

confidence must have a greater likelihood of being correct. To examine whether initial confidence is associated with initial correctness, we calculated the gamma correlation between correctness and confidence in the answer before discussion, as shown in the first column of Table 4 . The average gamma correlation between initial confidence and initial correctness (mean $(M)=0.40)$ was greater than zero, $t(160)=8.59, p<0.001, d=0.68$, indicating that greater confidence was associated with being correct.

Changing from an incorrect to a correct answer, then, may be driven entirely by selecting the answer from the peer with the greater confidence during discussion, even though most of the students in our sample were not required to explicitly disclose their confidence to their partner during discussion. We examined how frequently students choose the more confident answer when peers disagree. When peers disagreed, students' final answers aligned with the more confident peer only $58 \%$ of the time. Similarly, we tested what the performance would be if peers always picked the answer of the more confident peer. If peers always chose the more confident answer during discussion, the final accuracy would be $69 \%$, which is significantly lower than actual final accuracy $(M=72 \%$, $t(207)=2.59, p=0.01, d=0.18)$. While initial confidence is related to accuracy, these results show that confidence is not the only predictor of switching answers.

\section{Does correctness predict switching beyond confidence?}

Discussion may reveal information about the correctness of answers by generating new knowledge and testing the coherence of each possible answer. To test whether the correctness of an answer added predictive power beyond the confidence of the peers involved in discussion, we analyzed situations in which students disagreed with their partner. Out of the instances when partners initially disagreed, we predicted the likelihood of keeping one's answer based upon

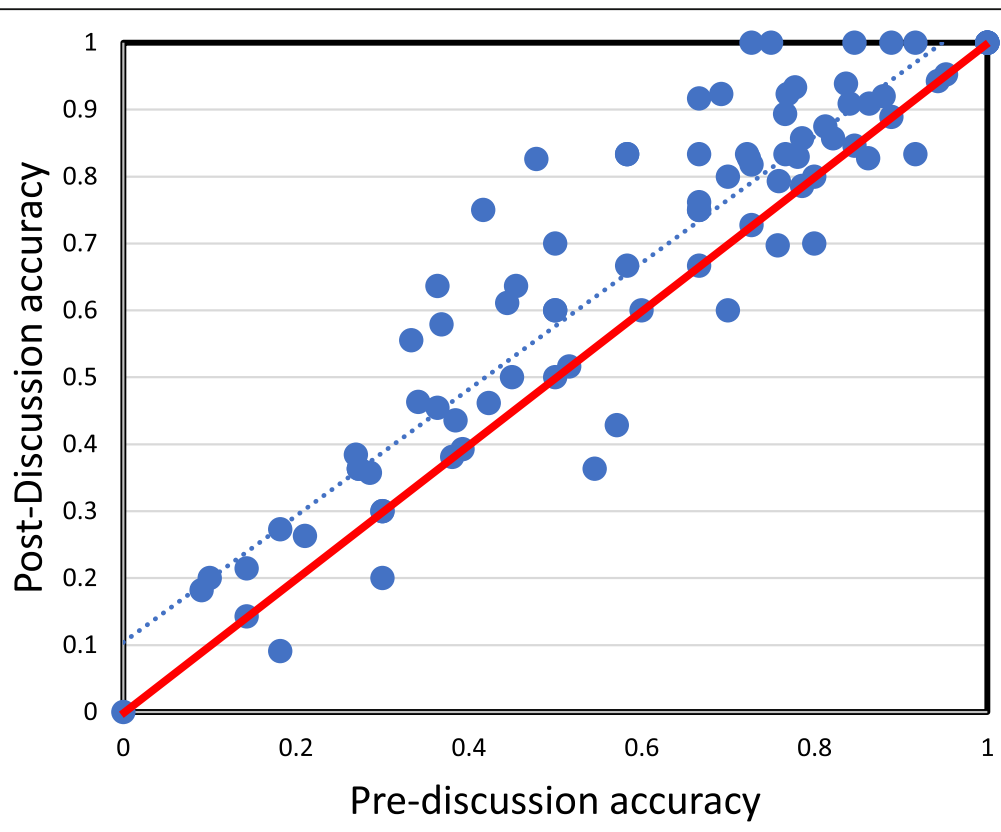

Fig. 1 The relationship between pre-discussion accuracy ( $x$ axis) and post-discussion accuracy (y axis). Each point represents a single question. The solid diagonal line represents equal pre-discussion and post-discussion accuracy; points above the line indicate improvements in accuracy and points below represent decrements in accuracy. The dashed line indicates the line of best fit for the observed data 


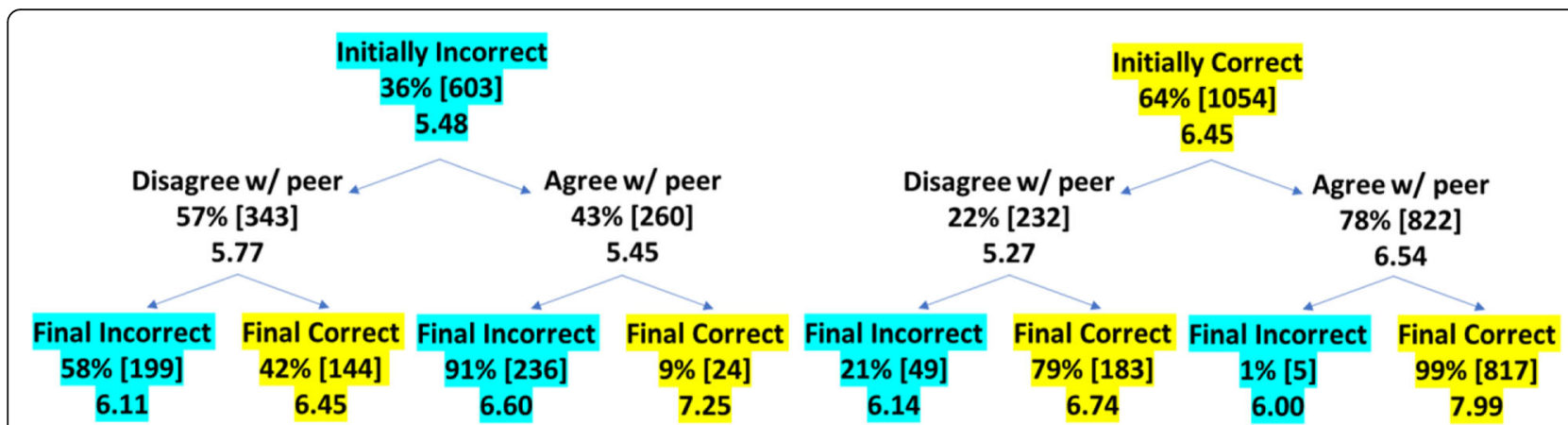

Fig. 2 The pathways of answers from pre-discussion (top row) to post-discussion (bottom row). Percentages indicate the portion of items from the category immediately above in that category, the numbers in brackets indicate the raw numbers of items, and the numbers at the bottom of each entry indicate the confidence associated with those items. In the middle, white row, confidence values show the peer's confidence.

Turquoise indicates incorrect answers and yellow indicates correct answers

one's own confidence, the partner's confidence, and whether one's answer was initially correct. The results of a model predicting whether students keep their answers is shown in Table 5. For each increase in a point of one's own confidence, the odds of keeping one's answer increases 1.25 times (95\% conf 1.13-1.38). For each decrease in a point of the partner's confidence, the odds of keeping one's answer increased 1.19 times $(1.08-1.32)$. The beta weight for one's confidence did not differ from the beta weight of the partner's confidence, $\chi^{2}=0.49, p=0.48$. Finally, if one's own answer was correct, the odds of keeping one's answer increased 4.48 times (2.92-6.89). In other words, the more confident students were, the more likely they were to keep their answer; the more confident their peer was, the more likely they were to change their answer; and finally, if a student was correct, they were more likely to keep their answer.

To illustrate this relationship, we plotted the probability of keeping one's own answer as a function of the difference between one's own and their partner's confidence for initially correct and incorrect answers. As shown in Fig. 3, at every confidence level, being correct led to equal or more frequently keeping one's answer than being incorrect.

As another measure of whether discussion allows learners to test the coherence of the correct answer, we analyzed how discussion impacted confidence when partners' answers agreed. We predicted confidence in answers by the interaction of time point (i.e., prediscussion versus post-discussion) and being initially correct for situations in which peers initially agreed on their answer. The results, displayed in Table 6, show that confidence increased from pre-discussion to postdiscussion by 1.08 points and that confidence was greater for initially correct answers (than incorrect answers) by 0.78 points. As the interaction between time point and initial correctness shows, confidence increased more from pre-discussion to post-discussion when students were initially correct (as compared to initially incorrect). To illustrate this relationship, we plotted preconfidence against post-confidence for initially correct and initially incorrect answers when peers agreed (Fig. 4). Each plotted point represents a student; the diagonal blue line indicates no change between pre-confidence and post-confidence. The graph reflects that confidence increases more from pre-discussion to post-discussion for correct answers than for incorrect answers, even when we only consider cases where peers agreed.

If students engage in more comprehensive answer testing during discussion than before, the relationship

Table 4 The gamma correlation between accuracy and confidence before and after discussion for each class

\begin{tabular}{|c|c|c|c|c|c|}
\hline Class & Pre-gamma & Post-gamma & SD of difference & Paired $t$ test comparing pre to post ${ }^{a}$ & Cohen's $d$ \\
\hline Cognitive Psych (Psych) 2015 & 0.60 & 0.79 & 0.52 & $t(18)=1.22, p=0.24$ & 0.29 \\
\hline Cognitive Psych (Psych) 2017 & 0.27 & 0.40 & 0.74 & $t(37)=2.29, p=0.02$ & 0.38 \\
\hline Decision Making (Ed Psych) 2016 & 0.36 & 0.56 & 0.46 & $t(22)=3.21, p=0.004$ & 0.47 \\
\hline Decision Making (Ed Psych) 2017 & 0.47 & 0.44 & 0.46 & $t(33)=0.24, p=0.81$ & -0.04 \\
\hline Learning Theories (Ed Psych) 2016 & 0.18 & 0.28 & 0.45 & $t(11)=1.57, p=0.14$ & 0.23 \\
\hline Learning Theories (Ed Psych) 2018 & 0.43 & 0.37 & 0.37 & $t(13)=0.58, p=0.57$ & -0.16 \\
\hline Overall & 0.40 & 0.48 & 0.55 & $t(139)=2.98, p=0.003$ & 0.24 \\
\hline
\end{tabular}

aGamma correlation requires that learners have variance in both confidence and correctness before and after discussion. Degrees of freedom are reduced because many students did not have requisite variation 
Table $\mathbf{5}$ Logit mixed-level regression analysis

\begin{tabular}{lllll}
\hline Fixed effect & $\hat{\beta}$ & $\mathrm{SE}$ & Wald z & $p$ \\
\hline Intercept & -0.18 & 0.13 & 1.36 & .17 \\
Own confidence (mean-centered) & 0.22 & 0.05 & 4.16 & $<.0001$ \\
Partner confidence (mean-centered) & -0.18 & 0.05 & 3.51 & .0005 \\
Own correct & 1.50 & 0.22 & 6.73 & $<.0001$ \\
\hline
\end{tabular}

The results of a logit mixed level regression predicting keeping one's answer from one's own confidence, the peer's confidence, and the correctness of one's initial answer for situations in which peers initially disagreed

between confidence in their answer and the accuracy of their answer should be stronger following discussion than it is before. We examined whether confidence accurately reflected correctness before and after discussion. To do so, we calculated the gamma correlation between confidence and accuracy, as is typically reported in the literature on metacognitive monitoring (e.g., Son \& Metcalfe, 2000; Tullis \& Fraundorf, 2017). Across all students, the resolution of metacognitive monitoring increases from pre-discussion to postdiscussion $(t(139)=2.98, p=0.003, d=0.24$; for a breakdown of gamma calculations for each class, see Table 4). Confidence was more accurately aligned with accuracy following discussion than preceding it. The resolution between student confidence and correctness increases through discussion, suggesting that discussion offers better coherence testing than answering alone.

\section{Discussion}

To examine why peer instruction benefits student learning, we analyzed student answers and confidence before
Table 6 Mixed-level regression analysis of predicting confidence

\begin{tabular}{lllll}
\hline Fixed effect & $\hat{\beta}$ & SE & $t$ value & $p$ \\
\hline Intercept & 5.63 & 0.21 & 26.66 & \\
Time point (pre vs post) & 1.08 & 0.14 & 7.98 & $<.0001$ \\
Initial correct & 0.78 & 0.13 & 6.05 & $<.0001$ \\
Time Point* Initial correct & 0.33 & 0.15 & 2.14 & .03 \\
\hline
\end{tabular}

The results of the mixed level regression predicting confidence in one's answer from the time point (pre- or post- discussion), the correctness of one's answer, and their interaction for situations in which peers initially agreed

and after discussion across six psychology classes. Discussing a question with a partner improved accuracy across classes and grade levels with small to mediumsized effects. Questions of all difficulty levels benefited from peer discussion; even questions where less than half of students originally answered correctly saw improvements from discussion. Benefits across the spectrum of question difficulty align with prior research showing improvements when even very few students initially know the correct answer (Smith et al., 2009). More students switched from incorrect answers to correct answers than vice versa, leading to an improvement in accuracy following discussion. Answer switching was driven by a student's own confidence in their answer and their partner's confidence. Greater confidence in one's answer indicated a greater likelihood of keeping the answer; a partner's greater confidence increased the likelihood of changing to their answer.

Switching answers depended on more than just confidence: even when accounting for students' confidence

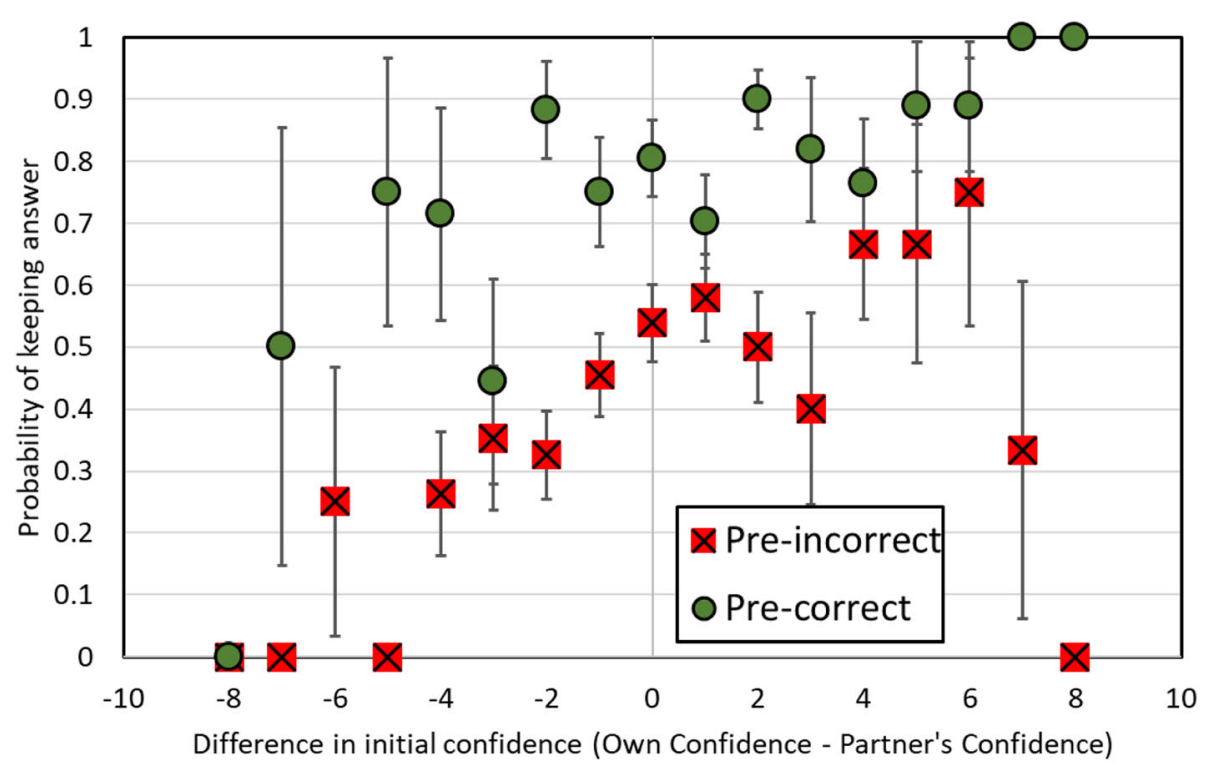

Fig. 3 The probability of keeping one's answer in situations where one's partner initially disagreed as a function of the difference between partners' levels of confidence. Error bars indicate the standard error of the proportion and are not shown when the data are based upon a single data point 


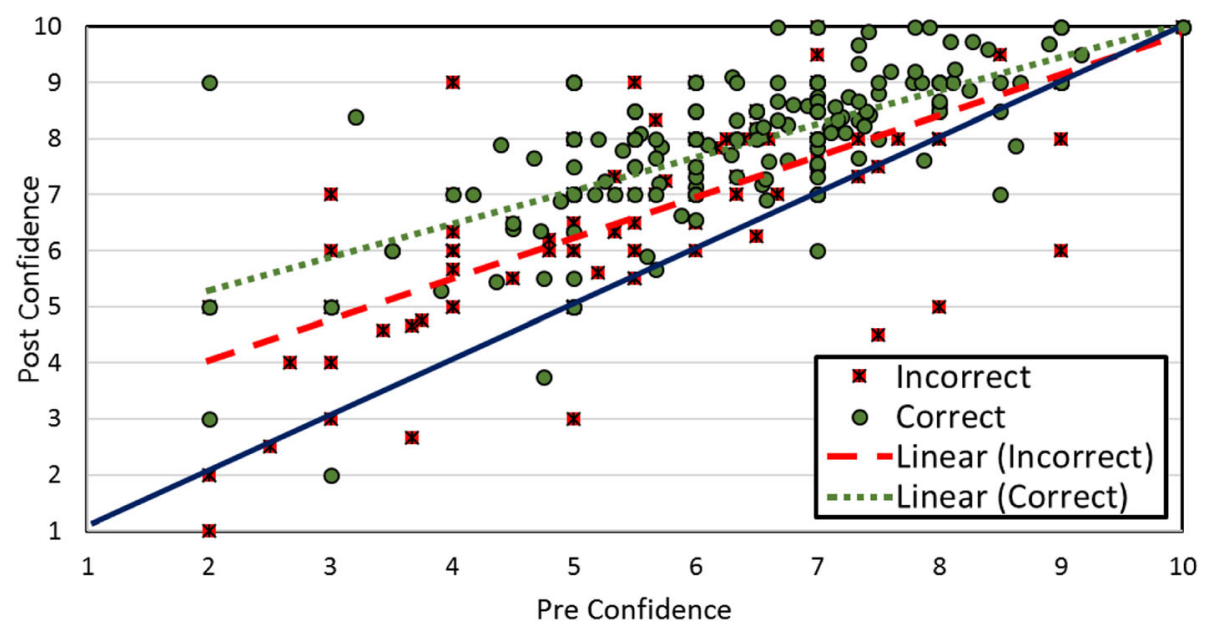

Fig. 4 The relationship between pre-discussion and post-discussion confidence as a function of the accuracy of an answer when partners agreed. Each dot represents a student

levels, the correctness of the answer impacted switching behavior. Across several measures, our data showed that the correctness of an answer carried weight beyond confidence. For example, the correctness of the answer predicted whether students switched their initial answer during peer disagreements, even after taking the confidence of both partners into account. Further, students' confidence increased more when partners agreed on the correct answer compared to when they agreed on an incorrect answer. Finally, although confidence increased from pre-discussion to post-discussion when students changed their answers from incorrect to the correct ones, confidence decreased when students changed their answer away from the correct one. A plausible interpretation of this difference is that when students switch from a correct answer to an incorrect one, their decrease in confidence reflects the poor coherence of their final incorrect selection.

Whether peer instruction resulted in optimal switching behaviors is debatable. While accuracy improved through discussion, final accuracy was worse than if students had optimally switched their answers during discussion. If students had chosen the correct answer whenever one of the partners initially chose it, the final accuracy would have been significantly higher $(\mathrm{M}=0.80$ $(\mathrm{SD}=0.19))$ than in our data $(\mathrm{M}=0.72(\mathrm{SD}=0.24), t$ $(207)=6.49, p<0.001, d=0.45)$. While this might be interpreted as "process loss" (Steiner, 1972; Weldon \& Bellinger, 1997), that would assume that there is sufficient information contained within the dyad to ascertain the correct answer. One individual selecting the correct answer is inadequate for this claim because they may not have a compelling justification for their answer. When we account for differences in initial confidence, students' final accuracy was better than expected. Students' final accuracy was better than that predicted from a model in which students always choose the answer of the more confident peer. This over-performance, often called "process gain", can sometimes emerge when individuals collaborate to create or generate new knowledge (Laughlin, Bonner, \& Miner, 2002; Michaelsen, Watson, \& Black, 1989; Sniezek \& Henry, 1989; Tindale \& Sheffey, 2002). Final accuracy reveals that students did not simply choose the answer of the more confident student during discussion; instead, students more thoroughly probed the coherence of answers and mental models during discussion than they could do alone.

Students' final accuracy emerges from the interaction between the pairs of students, rather than solely from individuals' sequestered knowledge prior to discussion (e.g. Wegner, Giuliano, \& Hertel, 1985). Schwartz (1995) details four specific cognitive products that can emerge through working in dyads. Specifically, dyads force verbalization of ideas through discussion, and this verbalization facilitates generating new knowledge. Students may not create a coherent explanation of their answer until they engage in discussion with a peer. When students create a verbal explanation of their answer to discuss with a peer, they can identify knowledge gaps and construct new knowledge to fill those gaps. Prior research examining the content of peer interactions during argumentation in upper-level biology classes has shown that these kinds of co-construction happen frequently; over three quarters of statements during discussion involve an exchange of claims and reasoning to support those claims (Knight et al., 2013). Second, dyads have more information processing resources than individuals, so they can solve more complex problems. Third, dyads may foster greater motivation than individuals. Finally, dyads may stimulate the creation of new, abstract representations of knowledge, above and beyond what one would expect from the level of abstraction created by individuals. Students need 
to communicate with their partner; to create common ground and facilitate discourse, dyads negotiate common representations to coordinate different perspectives. The common representations bridge multiple perspectives, so they lose idiosyncratic surface features of individuals' representation. Working in pairs generates new knowledge and tests of answers that could not be predicted from individuals' performance alone.

More broadly, teachers often put students in groups so that they can learn from each other by giving and receiving help, recognizing contradictions between their own and others' perspectives, and constructing new understandings from divergent ideas (Bearison, Magzamen, \& Filardo, 1986; Bossert, 1988-1989; Brown \& Palincsar, 1989; Webb \& Palincsar, 1996). Giving explanations to a peer may encourage explainers to clarify or reorganize information, recognize and rectify gaps in understandings, and build more elaborate interpretations of knowledge than they would have alone (Bargh \& Schul, 1980; Benware \& Deci, 1984; King, 1992; Yackel, Cobb, \& Wood, 1991). Prompting students to explain why and how problems are solved facilitates conceptual learning more than reading the problem solutions twice without self-explanations (Chi, de Leeuw, Chiu, \& LaVancher, 1994; Rittle-Johnson, 2006; Wong, Lawson, \& Keeves, 2002). Self-explanations can prompt students to retrieve, integrate, and modify their knowledge with new knowledge; self-explanations can also help students identify gaps in their knowledge (Bielaczyc, Pirolli, \& Brown, 1995; Chi \& Bassock, 1989; Chi, Bassock, Lewis, Reimann, \& Glaser, 1989; Renkl, Stark, Gruber, \& Mandl, 1998; VanLehn, Jones, \& Chi, 1992; Wong et al., 2002), detect and correct errors, and facilitate deeper understanding of conceptual knowledge (Aleven \& Koedinger, 2002; Atkinson, Renkl, \& Merrill, 2003; Chi \& VanLehn, 2010; Graesser, McNamara, \& VanLehn, 2005). Peer instruction, while leveraging these benefits of self-explanation, also goes beyond them by involving what might be called "other-explanation" processes - processes recruited not just when explaining a situation to oneself but to others. Mercier and Sperber (2019) argue that much of human reason is the result of generating explanations that will be convincing to other members of one's community, thereby compelling others to act in the way that one wants.

Conversely, students receiving explanations can fill in gaps in their own understanding, correct misconceptions, and construct new, lasting knowledge. Fellow students may be particularly effective explainers because they can better take the perspective of their peer than the teacher (Priniski \& Horne, 2019; Ryskin, Benjamin, Tullis, \& Brown-Schmidt, 2015; Tullis, 2018). Peers may be better able than expert teachers to explain concepts in familiar terms and direct peers' attention to the relevant features of questions that they do not understand (Brown \& Palincsar, 1989; Noddings, 1985; Vedder, 1985; Vygotsky, 1981).
Peer instruction may benefit from the generation of explanations, but social influences may compound those benefits. Social interactions may help students monitor and regulate their cognition better than self-explanations alone (e.g., Jarvela et al., 2015; Kirschner, Kreijns, Phielix, \& Fransen, 2015; Kreijns, Kirschner, \& Vermeulen, 2013; Phielix, Prins, \& Kirschner, 2010; Phielix, Prins, Kirschner, Erkens, \& Jaspers, 2011). Peers may be able to judge the quality of the explanation better than the explainer. In fact, recent research suggests that peer instruction facilitates learning even more than self-explanations (Versteeg, van Blankenstein, Putter, \& Steendijk, 2019).

Not only does peer instruction generate new knowledge, but it may also improve students' metacognition. Our data show that peer discussion prompted more thorough testing of the coherence of the answers. Specifically, students' confidences were better aligned with accuracy following discussion than before. Improvements in metacognitive resolution indicate that discussion provides more thorough testing of answers and ideas than does answering questions on one's own. Discussion facilitates the metacognitive processes of detecting errors and assessing the coherence of an answer.

Agreement among peers has important consequences for final behavior. For example, when peers agreed, students very rarely changed their answer (less than 3\% of the time). Further, large increases in confidence occurred when students agreed (as compared to when they disagreed). Alternatively, disagreements likely engaged different discussion processes and prompted students to combine different answers. Whether students weighed their initial answer more than their partner's initial answer remains debatable. When students disagreed with their partner, they were more likely to stick with their own answer than switch; they kept their own answer $66 \%$ of the time. Even when their partner was more confident, students only switched to their partner's answer $50 \%$ of the time. The low rate of switching during disagreements suggests that students weighed their own answer more heavily than their partner's answer. In fact, across prior research, deciders typically weigh their own thoughts more than the thoughts of an advisor (Harvey, Harries, \& Fischer, 2000; Yaniv \& Kleinberger, 2000).

Interestingly, peers agreed more frequently than expected by chance. When students were initially correct $(64 \%$ of the time), $78 \%$ of peers agreed. When students were initially incorrect (36\% of the time), peers agreed $43 \%$ of the time. Pairs of students, then, agree more than expected by a random distribution of answers throughout the classroom. These data suggest that students group themselves into pairs based upon likelihood of sharing the same answer. Further, these data suggest that student understanding is not randomly distributed throughout the physical space of the classroom. Across all classes, students were instructed to work with a 
neighbor to discuss their answer. Given that neighbors agreed more than predicted by chance, students seem to tend to sit near and pair with peers that share their same levels of understanding. Our results from peer instruction reveal that students physically locate themselves near students of similar abilities. Peer instruction could potentially benefit from randomly pairing students together (i.e. not with a physically close neighbor) to generate the most disagreements and generative activity during discussion.

Learning through peer instruction may involve deep processing as peers actively challenge each other, and this deep processing may effectively support long-term retention. Future research can examine the persistence of gains in accuracy from peer instruction. For example, whether errors that are corrected during peer instruction stay corrected on later retests of the material remains an open question. High and low-confidence errors that are corrected during peer instruction may result in different long-term retention of the correct answer; more specifically, the hypercorrection effect suggests that errors committed with high confidence are more likely to be corrected on subsequent tests than errors with low confidence (e.g., Butler, Fazio, \& Marsh, 2011; Butterfield \& Metcalfe, 2001; Metcalfe, 2017). Whether hypercorrection holds for corrections from classmates during peer instruction (rather than from an absolute authority) could be examined in the future.

The influence of partner interaction on accuracy may depend upon the domain and kind of question posed to learners. For simple factual or perceptual questions, partner interaction may not consistently benefit learning. More specifically, partner interaction may amplify and bolster wrong answers when factual or perceptual questions lead most students to answer incorrectly (Koriat, 2015). However, for more "intellective tasks," interactions and arguments between partners can produce gains in knowledge (Trouche et al., 2014). For example, groups typically outperform individuals for reasoning tasks (Laughlin, 2011; Moshman \& Geil, 1998), math problems (Laughlin \& Ellis, 1986), and logic problems (Doise \& Mugny, 1984; Perret-Clermont, 1980). Peer instruction questions that allow for student argumentation and reasoning, therefore, may have the best benefits in student learning.

The underlying benefits of peer instruction extend beyond the improvements in accuracy seen from prediscussion to post-discussion. Peer instruction prompts students to retrieve information from long-term memory, and these practice tests improve long-term retention of information (Roediger III \& Karpicke, 2006; Tullis, Fiechter, \& Benjamin, 2018). Further, feedback provided by instructors following peer instruction may guide students to improve their performance and correct misconceptions, which should benefit student learning (Bangert-Drowns, Kulik, \& Kulik, 1991; Thurlings, Vermeulen, Bastiaens, \&
Stijnen, 2013). Learners who engage in peer discussion can use their new knowledge to solve new, but similar problems on their own (Smith et al., 2009). Generating new knowledge and revealing gaps in knowledge through peer instruction, then, effectively supports students' ability to solve novel problems. Peer instruction can be an effective tool to generate new knowledge through discussion between peers and improve student understanding and metacognition.

\section{Acknowledgements \\ Not applicable.}

\section{Authors' contributions}

JGT collected some data, analyzed the data, and wrote the first draft of the paper. RLG collected some data, contributed significantly to the framing of the paper, and edited the paper. The authors read and approved the final manuscript.

\section{Authors' information}

JGT: Assistant Professor in Educational Psychology at University of Arizona. RLG: Chancellor's Professor in Psychology at Indiana University.

\section{Funding}

No funding supported this manuscript.

\section{Availability of data and materials}

As described below, data and materials are available on the

OpenScienceFramework: https://mfr.osf.io/render?url=https://osf.io/5qc46/

?action=download\%26mode=render.

\section{Ethics approval and consent to participate}

The ethics approval was waived by the Indiana University Institutional Review Board (IRB) and the University of Arizona IRB, given that these data are collected as part of normal educational settings and processes.

\section{Consent for publication}

No individual data are presented in the manuscript.

\section{Competing interests}

The authors declare that they have no competing interests.

\section{Author details}

'Department of Educational Psychology, University of Arizona, $1430 \mathrm{E}$. Second St., Tucson, AZ 85721, USA. ${ }^{2}$ Department of Psychology, Indiana University, Bloomington, IN, USA.

Received: 8 October 2019 Accepted: 25 February 2020

Published online: 09 April 2020

\section{References}

Aleven, V., \& Koedinger, K. R. (2002). An effective metacognitive strategy: Learning by doing and explaining with a computer based cognitive tutor. Cognitive Science, 26, 147-179.

Atkinson, R. K., Renkl, A., \& Merrill, M. M. (2003). Transitioning from studying examples to solving problems: Effects of self-explanation prompts and fading worked-out steps. Journal of Educational Psychology, 95, 774-783.

Baayen, R. H. (2008). Analyzing linquistic data: A practical introduction to statistics. Cambridge: Cambridge University Press.

Baayen, R. H., Davidson, D. J., \& Bates, D. M. (2008). Mixed-effects modeling with crossed random effects for subjects and items. Journal of Memory and Language, 59, 390-412.

Bangert-Drowns, R. L., Kulik, J. A., \& Kulik, C.-L. C. (1991). Effects of frequent classroom testing. Journal of Educational Research, 85, 89-99.

Bargh, J. A., \& Schul, Y. (1980). On the cognitive benefit of teaching. Journal of Educational Psychology, 72, 593-604.

Bates, D., Maechler, M., Bolker, B., \& Walker, S. (2015). Fitting linear mixed-effects models using Ime4. Journal of Statistical Software, 67, 1-48.

Bearison, D. J., Magzamen, S., \& Filardo, E. K. (1986). Sociocognitive conflict and cognitive growth in young children. Merrill-Palmer Quarterly, 32(1), 51-72. 
Beatty, I. D., Gerace, W. J., Leonard, W. J., \& Dufresne, R. J. (2006). Designing effective questions for classroom response system teaching. American Journal of Physics, 74(1), 31e39.

Beekes, W. (2006). The "millionaire" method for encouraging participation. Active Learning in Higher Education, 7, 25-36.

Benware, C. A., \& Deci, E. L. (1984). Quality of learning with an active versus passive motivational set. American Educational Research Journal, 21, 755-765.

Bielaczyc, K., Pirolli, P., \& Brown, A. L. (1995). Training in self-explanation and self regulation strategies: Investigating the effects of knowledge acquisition activities on problem solving. Cognition and Instruction, 13, 221-251.

Bossert, S. T. (1988-1989). Cooperative activities in the classroom. Review of Research in Education, 15, 225-252.

Brooks, B. J., \& Koretsky, M. D. (2011). The influence of group discussion on students' responses and confidence during peer instruction. Journal of Chemistry Education, 88, 1477-1484.

Brown, A. L., \& Palincsar, A. S. (1989). Guided, cooperative learning and individual knowledge acquisition. In L. B. Resnick (Ed.), Knowing, learning, and instruction: essays in honor of Robert Glaser, (pp. 393-451). Hillsdale: Erlbaum.

Butchart, S., Handfield, T., \& Restall, G. (2009). Using peer instruction to teach philosophy, logic and critical thinking. Teaching Philosophy, 32, 1-40.

Butler, A. C., Fazio, L. K., \& Marsh, E. J. (2011). The hypercorrection effect persists over a week, but high-confidence errors return. Psychonomic Bulletin \& Review, 18(6), 1238-1244.

Butterfield, B., \& Metcalfe, J. (2001). Errors committed with high confidence are hypercorrected. Journal of Experimental Psychology: Learning, Memory, and Cognition, 27(6), 1491

Caldwell, J. E. (2007). Clickers in the large classroom: current research and bestpractice tips. CBE-Life Sciences Education, 6(1), 9-20.

Chi, M., \& VanLehn, K. A. (2010). Meta-cognitive strategy instruction in intelligent tutoring systems: How, when and why. Journal of Educational Technology and Society, 13, 25-39.

Chi, M. T. H., \& Bassock, M. (1989). Learning from examples via self-explanations. In L. B. Resnick (Ed.), Knowing, learning, and instruction: Essays in honor of Robert Glaser, (pp. 251-282). Hillsdale: Erlbaum.

Chi, M. T. H., Bassock, M., Lewis, M., Reimann, P., \& Glaser, R. (1989). Selfexplanations: How students study and use examples in learning to solve problems. Cognitive Science, 13, 145-182.

Chi, M. T. H., de Leeuw, N., Chiu, M. H., \& LaVancher, C. (1994). Eliciting selfexplanations improves understanding. Cognitive Science, 18, 439-477.

Cortright, R. N., Collins, H. L., \& DiCarlo, S. E. (2005). Peer instruction enhanced meaningful learning: Ability to solve novel problems. Advances in Physiology Education, 29, 107-111.

Crouch, C. H., \& Mazur, E. (2001). Peer instruction: Ten years of experience and results. American Journal of Physics, 69, 970-977.

Cummings, K. \& Roberts, S. (2008). A study of peer instruction methods with school physics students. In C. Henderson, M. Sabella, \& L. Hsu (Eds.), Physics education research conference, (pp. 103-106). College Park: American Institute of Physics.

Deslauriers, L., Schelew, E., \& Wieman, C. (2011). Improved learning in a largeenrollment physics class. Science, 332, 862-864

Duncan, D. (2005). Clickers in the classroom: How to enhance science teaching using classroom response systems. San Francisco: Pearson/Addison-Wesley.

Finley, J. R., Tullis, J. G., \& Benjamin, A. S. (2010). Metacognitive control of learning and remembering. In M. S. Khine, \& I. M. Saleh (Eds.), New science of learning: Cognition, computers and collaborators in education. New York: Springer Science \& Business Media, LLC.

Giuliodori, M. J., Lujan, H. L., \& DiCarlo, S. E. (2006). Peer instruction enhanced student performance on qualitative problem solving questions. Advances in Physiology Education, 30, 168-173.

Graesser, A. C., McNamara, D., \& VanLehn, K. (2005). Scaffolding deep comprehension strategies through AutoTutor and iSTART. Educational Psychologist, 40, 225-234.

Granovskiy, B., Gold, J. M., Sumpter, D., \& Goldstone, R. L. (2015). Integration of social information by human groups. Topics in Cognitive Science, 7, 469-493.

Harvey, N., \& Fischer, I. (1997). Taking advice: Accepting help, improving judgment, and sharing responsibility. Organizational Behavior and Human Decision Processes, 70, 117-133.

Harvey, N., Harries, C., \& Fischer, I. (2000). Using advice and assessing its quality. Organizational Behavior and Human Decision Processes, 81, 252-273.

Henderson, C., \& Dancy, M. H. (2009). The impact of physics education research on the teaching of introductory quantitative physics in the United States. Physical Review Special Topics: Physics Education Research, 5(2), 020107.
Jaeger, T. F. (2008). Categorical data analysis: away from ANOVAs (transformation or not) and towards logit mixed models. Journal of Memory and Language, 59, 434-446.

James, M. C. (2006). The effect of grading incentive on student discourse in peer instruction. American Journal of Physics, 74(8), 689-691.

Jarvela, S., Kirschner, P., Panadero, E., Malmberg, J., Phielix, C., Jaspers, J., ... Jarvenoja, H. (2015). Enhancing socially shared regulation in collaborative learning groups: Designing for CSCL regulation tools. Educational Technology Research and Development, 63(1), 125e142.

Jones, M. E., Antonenko, P. D., \& Greenwood, C. M. (2012). The impact of collaborative and individualized student response system strategies on learner motivation, metacognition, and knowledge transfer. Journal of Computer Assisted Learning, 28(5), 477-487.

King, A. (1992). Facilitating elaborative learning through guided studentgenerated questioning. Educational Psychologist, 27, 111-126.

Kirschner, P. A., Kreijns, K., Phielix, C., \& Fransen, J. (2015). Awareness of cognitive and social behavior in a CSCL environment. Journal of Computer Assisted Learning, 31(1), 59-77.

Knight, J. K., Wise, S. B., \& Southard, K. M. (2013). Understanding clicker discussions: student reasoning and the impact of instructional cues. CBE-Life Sciences Education, 12, 645-654.

Koriat, A. (2015). When two heads are better than one and when they can be worse: The amplification hypothesis. Journal of Experimental Psychology: General, 144, 934-950. https://doi.org/10.1037/xge0000092.

Kreijns, K., Kirschner, P. A., \& Vermeulen, M. (2013). Social aspects of CSCL environments: A research framework. Educational Psychologist, 48(4), 229e242.

Kuhn, L. M., \& Sniezek, J. A. (1996). Confidence and uncertainty in judgmental forecasting: Differential effects of scenario presentation. Journal of Behavioral Decision Making, 9, 231-247.

Lasry, N., Mazur, E., \& Watkins, J. (2008). Peer instruction: From Harvard to the two-year college. American Journal of Physics, 76(11), 1066-1069.

Laughlin, P. R. (2011). Group problem solving. Princeton: Princeton University Press.

Laughlin, P. R., Bonner, B. L., \& Miner, A. G. (2002). Groups perform better than individuals on letters-to-numbers problems. Organisational Behaviour and Human Decision Processes, 88, 605-620.

Laughlin, P. R., \& Ellis, A. L. (1986). Demonstrability and social combination processes on mathematical intellective tasks. Journal of Experimental Social Psychology, 22, 177-189.

Lucas, A. (2009). Using peer instruction and i-clickers to enhance student participation in calculus. Primus, 19(3), 219-231.

Mazur, E. (1997). Peer instruction: A user's manual. Upper Saddle River: Prentice Hall.

Mercier, H., \& Sperber, D. (2019). The enigma of reason. Cambridge: Harvard University Press.

Metcalfe, J. (2017). Learning from errors. Annual Review of Psychology, 68, 465-489.

Michaelsen, L. K., Watson, W. E., \& Black, R. H. (1989). Realistic test of individual versus group decision making. Journal of Applied Psychology, 64, 834-839.

Miller, R. L., Santana-Vega, E., \& Terrell, M. S. (2007). Can good questions and peer discussion improve calculus instruction? Primus, 16(3), 193-203.

Morgan, J. T., \& Wakefield, C. (2012). Who benefits from peer conversation? Examining correlations of clicker question correctness and course performance. Journal of College Science Teaching, 41(5), 51-56.

Moshman, D., \& Geil, M. (1998). Collaborative reasoning: Evidence for collective rationality. Thinking and Reasoning, 4, 231-248.

Murayama, K., Sakaki, M., Yan, V. X., \& Smith, G. M. (2014). Type I error inflation in the traditional by-participant analysis to metamemory accuracy: A generalized mixed-effects model perspective. Journal of Experimental Psychology: Learning, Memory, and Cognition, 40, 1287-1306.

Newbury, P., \& Heiner, C. (2012). Ready, set, react! getting the most out of peer instruction using clickers. Retrieved October 28, 2015, from http://www.cwsei. ubc.ca/Files/ReadySetReact_3fold.pdf.

Nielsen, K. L., Hansen-Nygård, G., \& Stav, J. B. (2012). Investigating peer instruction: how the initial voting session affects students' experiences of group discussion. ISRN Education, 2012, article 290157.

Noddings, N. (1985). Small groups as a setting for research on mathematical problem solving. In E. A. Silver (Ed.), Teaching and learning mathematical problem solving, (pp. 345-360). Hillsdale: Erlbaum.

Perret-Clermont, A. N. (1980). Social Interaction and Cognitive Development in Children. London: Academic Press.

Perez, K. E., Strauss, E. A., Downey, N., Galbraith, A., Jeanne, R., Cooper, S., \& Madison, W. (2010). Does displaying the class results affect student discussion during peer instruction? CBE Life Sciences Education, 9, 133-140. 
Phielix, C., Prins, F. J., \& Kirschner, P. A. (2010). Awareness of group performance in a CSCL-environment: Effects of peer feedback and reflection. Computers in Human Behavior, 26(2), 151-161.

Phielix, C., Prins, F. J., Kirschner, P. A., Erkens, G., \& Jaspers, J. (2011). Group awareness of social and cognitive performance in a CSCL environment: Effects of a peer feedback and reflection tool. Computers in Human Behavior, 27(3), 1087-1102

Pollock, S. J., Chasteen, S. V., Dubson, M., \& Perkins, K. K. (2010). The use of concept tests and peer instruction in upper-division physics. In M. Sabella, C. Singh, \& S. Rebello (Eds.), AIP conference proceedings, (vol. 1289, p. 261). New York: AIP Press.

Porter, L., Bailey-Lee, C., \& Simon, B. (2013). Halving fail rates using peer instruction: A study of four computer science courses. In SIGCSE '13: Proceedings of the 44th ACM technical symposium on computer science education, (pp. 177-182). New York: ACM Press.

Price, P. C., \& Stone, E. R. (2004). Intuitive evaluation of likelihood judgment producers. Journal of Behavioral Decision Making, 17, 39-57.

Priniski, J. H., \& Horne, Z. (2019). Crowdsourcing effective educational interventions. In A. K. Goel, C. Seifert, \& C. Freska (Eds.), Proceedings of the 41st annual conference of the cognitive science society. Austin: Cognitive Science Society.

Rao, S. P., \& DiCarlo, S. E. (2000). Peer instruction improves performance on quizzes. Advances in Physiological Education, 24, 51-55.

Renkl, A., Stark, R., Gruber, H., \& Mandl, H. (1998). Learning from worked-out examples: The effects of example variability and elicited self-explanations. Contemporary Educational Psychology, 23, 90-108.

Rittle-Johnson, B. (2006). Promoting transfer: Effects of self-explanation and direct instruction. Child Development, 77, 1-15.

Roediger III, H. L., \& Karpicke, J. D. (2006). Test-enhanced learning: Taking memory tests improves long-term retention. Psychological Science, 17, 249-255.

Ryskin, R., Benjamin, A. S., Tullis, J. G., \& Brown-Schmidt, S. (2015). Perspectivetaking in comprehension, production, and memory: An individual differences approach. Journal of Experimental Psychology: General, 144, 898-915.

Sah, S., Moore, D. A., \& MacCoun, R. J. (2013). Cheap talk and credibility: The consequences of confidence and accuracy on advisor credibility and persuasiveness. Organizational Behavior and Human Decision Processes, 121, 246-255.

Schwartz, D. L. (1995). The emergence of abstract representations in dyad problem solving. The Journal of the Learning Sciences, 4, 321-354.

Simon, B., Kohanfars, M., Lee, J., Tamayo, K., \& Cutts, Q. (2010). Experience report: peer instruction in introductory computing. In Proceedings of the 41st SIGCSE technical symposium on computer science education.

Smith, M. K., Wood, W. B., Adams, W. K., Wieman, C., Knight, J. K., Guild, N., \& Su, T. T. (2009). Why peer discussion improves student performance on in-class concept questions. Science, 323, 122-124.

Smith, M. K., Wood, W. B., Krauter, K., \& Knight, J. K. (2011). Combining peer discussion with instructor explanation increases student learning from inclass concept questions. CBE-Life Sciences Education, 10, 55-63.

Sniezek, J. A., \& Buckley, T. (1995). Cueing and cognitive conflict in judge-Advisor decision making. Organizational Behavior and Human Decision Processes, 62, 159-174.

Sniezek, J. A., \& Henry, R. A. (1989). Accuracy and confidence in group judgment. Organizational Behavior and Human Decision Processes, 43, 1-28.

Son, L. K., \& Metcalfe, J. (2000). Metacognitive and control strategies in study-time allocation. Journal of Experimental Psychology: Learning, Memory, and Cognition, 26, 204-221.

Steiner, I. D. (1972). Group processes and productivity. New York: Academic Press.

Thurlings, M., Vermeulen, M., Bastiaens, T., \& Stijnen, S. (2013). Understanding feedback: A learning theory perspective. Educational Research Review, 9, 1-15.

Tindale, R. S., \& Sheffey, S. (2002). Shared information, cognitive load, and group memory. Group Processes \& Intergroup Relations, 5(1), 5-18.

Trouche, E., Sander, E., \& Mercier, H. (2014). Arguments, more than confidence, explain the good performance of reasoning groups. Journal of Experimental Psychology: General, 143, 1958-1971.

Tullis, J. G. (2018). Predicting others' knowledge: Knowledge estimation as cueutilization. Memory \& Cognition, 46, 1360-1375.

Tullis, J. G., Fiechter, J. L., \& Benjamin, A. S. (2018). The efficacy of learners' testing choices. Journal of Experimental Psychology: Learning, Memory, and Cognition, 44, 540-552.

Tullis, J. G., \& Fraundorf, S. H. (2017). Predicting others' memory performance: The accuracy and bases of social metacognition. Journal of Memory and Language, 95, 124-137.

Turpen, C., \& Finkelstein, N. (2007). Understanding how physics faculty use peer instruction. In L. Hsu, C. Henderson, \& L. McCullough (Eds.), Physics education research conference, (pp. 204-209). College Park: American Institute of Physics.
Van Swol, L. M., \& Sniezek, J. A. (2005). Factors affecting the acceptance of expert advice. British Journal of Social Psychology, 44, 443-461.

VanLehn, K., Jones, R. M., \& Chi, M. T. H. (1992). A model of the self-explanation effect. Journal of the Learning Sciences, 2(1), 1-59.

Vedder, P. (1985). Cooperative learning: A study on processes and effects of cooperation between primary school children. Westerhaven: Rijkuniversiteit Groningen.

Versteeg, M., van Blankenstein, F. M., Putter, H., \& Steendijk, P. (2019). Peer instruction improves comprehension and transfer of physiological concepts: A randomized comparison with self-explanation. Advances in Health Sciences Education, 24, 151-165.

Vygotsky, L. S. (1981). The genesis of higher mental functioning. In J. V. Wertsch (Ed.), The concept of activity in Soviet psychology, (pp. 144-188). Armonk: Sharpe.

Webb, N. M., \& Palincsar, A. S. (1996). Group processes in the classroom. In D. C. Berliner, \& R. C. Calfee (Eds.), Handbook of educational psychology, (pp. 841-873). New York: Macmillan Library Reference USA: London: Prentice Hall International.

Wegner, D. M., Giuliano, T., \& Hertel, P. (1985). Cognitive interdependence in close relationships. In W. J. Ickes (Ed.), Compatible and incompatible relationships, (pp. 253-276). New York: Springer-Verlag.

Weldon, M. S., \& Bellinger, K. D. (1997). Collective memory: Collaborative and individual processes in remembering. Journal of Experimental Psychology: Learning, Memory, and Cognition, 23, 1160-1175.

Wieman, C., Perkins, K., Gilbert, S., Benay, F., Kennedy, S., Semsar, K., et al. (2009). Clicker resource guide: An instructor's guide to the effective use of personalresponse systems (clickers) in teaching. Vancouver: University of British Columbia Available from http://www.cwsei.ubc.ca/resources/files/Clicker_ guide_CWSEI_CU-SEl.pdf.

Wong, R. M. F., Lawson, M. J., \& Keeves, J. (2002). The effects of self-explanation training on students' problem solving in high school mathematics. Learning and Instruction, 12, 23.

Yackel, E., Cobb, P., \& Wood, T. (1991). Small-group interactions as a source of learning opportunities in second-grade mathematics. Journal for Research in Mathematics Education, 22, 390-408.

Yaniv, I. (2004a). The benefit of additional opinions. Current Directions in Psychological Science, 13, 75-78.

Yaniv, I. (2004b). Receiving other people's advice: Influence and benefit. Organizational Behavior and Human Decision Processes, 93, 1-13.

Yaniv, I., \& Choshen-Hillel, S. (2012). Exploiting the wisdom of others to make better decisions: Suspending judgment reduces egocentrism and increases accuracy. Journal of Behavioral Decision Making, 25, 427-434.

Yaniv, I., \& Kleinberger, E. (2000). Advice taking in decision making: Egocentric discounting and reputation formation. Organizational Behavior and Human Decision Processes, 83, 260-281.

\section{Publisher's Note}

Springer Nature remains neutral with regard to jurisdictional claims in published maps and institutional affiliations.

\section{Submit your manuscript to a SpringerOpen ${ }^{\circ}$ journal and benefit from:}

- Convenient online submission

Rigorous peer review

- Open access: articles freely available online

- High visibility within the field

- Retaining the copyright to your article

Submit your next manuscript at $>$ springeropen.com 